\title{
Impact of early intervention on the population prevalence of common mental disorders: 20-year prospective study
}

Paul Moran, Margarita Moreno-Betancur, Carolyn Coffey, Elizabeth A. Spry and George C. Patton

\section{Background}

The potential for early interventions to reduce the later prevalence of common mental disorders (CMD) first experienced in adolescence is unclear.

\section{Aims}

To examine the course of CMD and evaluate the extent to which the prevalence of $\mathrm{CMD}$ could be reduced by preventing adolescent $\mathrm{CMD}$, or by intervening to change four young adult processes, between the ages of 20 and 29 years, that could be mediating the link between adolescent and adult disorder.

\section{Method}

This was a prospective cohort study of 1923 Australian participants assessed repeatedly from adolescence (wave 1, mean age 14 years) to adulthood (wave 10, mean age 35 years) Causal mediation analysis was undertaken to evaluate the extent to which the prevalence of CMD at age 35 years in those with adolescent CMD could be reduced by either preventing adolescent $\mathrm{CMD}$, or by intervening on four young adult mediating processes: the occurrence of young adult CMD, frequent cannabis use, parenting a child by age 24 years, and engagement in higher education and employment.

\section{Results}

At age $35,19.2 \%$ of participants reported CMD; a quarter of these participants experienced CMD during both adolescence and young adulthood. In total, $49 \%$ of those with CMD during both adolescence and young adulthood went on to report CMD at age 35 years. Preventing adolescent CMD reduced the population prevalence at age 35 years by $3.9 \%$. Intervening on all four young adult processes among those with adolescent $C M D$, reduced this prevalence by $1.6 \%$.

\section{Conclusions}

In this Australian cohort, a large proportion of adolescent CMD resolved by adulthood, and by age 35 years, the largest proportion of CMD emerged among individuals without prior CMD. Time-limited, early intervention in those with earlier adolescent disorder is unlikely to substantially reduce the prevalence of CMD in midlife.

\section{Keywords}

Depressive disorders; anxiety disorders; epidemiology; outcome studies; statistical methodology.

\section{Copyright and usage}

(C) The Author(s), 2022. Published by Cambridge University Press on behalf of the Royal College of Psychiatrists. This is an Open Access article, distributed under the terms of the Creative Commons Attribution licence (https://creativecommons.org/ licenses/by/4.0/), which permits unrestricted re-use, distribution, and reproduction in any medium, provided the original work is properly cited.
Globally, over 300 million people experience depression and anxiety, with serious consequences for the health and wealth of individuals and wider society. Depression is the leading contributor to suicide deaths ${ }^{1}$ and anxiety disorders are the sixth largest contributor to non-fatal health loss. ${ }^{2}$ Findings from retrospective surveys in adults suggest that most common mental disorders (CMD) begin with an episode in adolescence. ${ }^{3}$ Recall biases mean that such studies have a limited ability to assess recovery from earlier disorders but, even so, their findings have supported the case for early intervention to reduce later burden of disease. ${ }^{4}$ Indeed, the development of mental health services for youth is widely viewed as a 'best buy' for reducing the prevalence, costs and morbidity arising from mental disorders. ${ }^{5}$ However, few prospective studies have tracked the natural history of CMD from adolescence through to the fourth decade of life ${ }^{6-9}$ and none have estimated the potential for early interventions to reduce their later adult prevalence, using causal analytic methods.

In this paper, we prospectively describe the course of CMD from adolescence to the fourth decade, examining the continuity and strength of associations between adolescent, young adult and adult disorders. Then, we applied causal analytic methods to evaluate the extent to which the prevalence of CMD at age 35 years could be reduced by either preventing adolescent $\mathrm{CMD}$, or by intervening in those with adolescent CMD to change four young adult processes, between the ages of 20 and 29 years, that could be mediating the link between adolescent and adult disorder. These were selected on $a$ priori grounds because of their strong links with adult CMD and their potential modifiability: the occurrence of $\mathrm{CMD},{ }^{10}$ cannabis use, ${ }^{11}$ parenting a child ${ }^{12}$ and engagement in higher education and employment. ${ }^{12}$

\section{Method}

\section{Study design and participants}

The Victorian Adolescent Health Cohort Study (VAHCS) is a longitudinal cohort study conducted in the state of Victoria, Australia (Fig. 1), commencing in 1992, in which we selected two classes at random from a stratified frame of 45 of government, Catholic and independent schools (total number of students 60 905). School retention rates to year 9 in the year of sampling was $98 \%$. The cohort was defined using a two-stage sampling procedure.

At stage one, 45 schools with multiple classes at each level were chosen at random with a probability proportional to the number of year 9 (aged 14-15 years) students in the schools in each stratum. At stage two, one single intact class was selected at random from each participating school in the latter part of the ninth school year (wave 1), and a second class from each school was selected 6 months later (wave 2), resulting in a close to representative sample of Victorian year 10 students in 1992. The sampling frame 


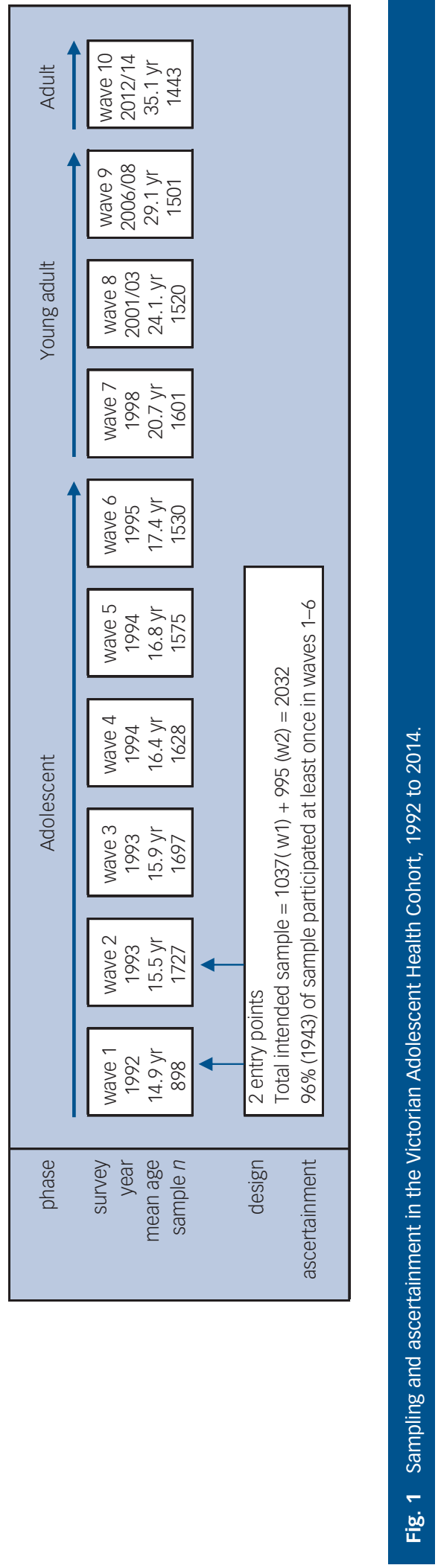

of 2032 individuals was complete at wave 2 . One school did not continue beyond wave 1 , causing a loss of 13 participants and leaving 44 schools in the study. The achieved sample was 1943 participants ( $96 \%$ of the sampling frame).

Participants were reviewed at four 6-month intervals between the ages of 15 and 18 years (waves 3-6) with four follow-up waves in adulthood, ages 20-21 years (wave 7), 24-25 years (wave 8), 28-29 years (wave 9) and 34-35 years (wave 10). After excluding 20 individuals who had died during the follow-up, the final analytic sample was 1923.

\section{Measures}

The conceptual model motivating the questions and guiding our analyses is shown in Fig. 2 with the measures described below.

CMD was assessed at waves 2 to 7 using the revised Clinical Interview Schedule (CIS-R). ${ }^{13}$ The total scores on the CIS-R were dichotomised at a cut-off point of $11 .^{13}$ At wave 8 , CMD symptoms were assessed with the 12-item General Health Questionnaire (GHQ-12), dichotomised at the cut-off point of $\geq 2 .{ }^{14}$ At waves 9 and 10, two additional measures of depression and anxiety were obtained using the Composite International Diagnostic Interview (CIDI) with the reference period of the past 12 months: major depressive disorder (MDD) and anxiety disorder, with both defined according to ICD-10, MDD assessed using the CIDIAuto $^{15}$ and anxiety disorder using the CIDI-Short Form. ${ }^{16}$ Participants were classified as having anxiety disorder if they were diagnosed with generalised anxiety disorder, social phobia, agoraphobia or panic disorder. Participants were identified with CMD by wave if they reached the threshold of any of these measures.

The main exposure, adolescent CMD, was defined as $\geq 2 v$. $<2$ waves of CMD in the adolescent phase (waves 2 to 6 ). We chose to define CMD in this way because this represents a level and persistence of a disorder where a clinical intervention is likely to be indicated ${ }^{13}$ and because prior evidence suggests that persisting adolescent disorder also carries the highest risk for continuity into young adulthood. ${ }^{6}$ Young adult CMD was similarly defined as $\geq 2$ $v .<2$ waves of CMD in the young adulthood phase (waves 7-9).

We conducted sensitivity analyses to explore whether a less restrictive definition of CMD in adolescence and young adulthood (the presence of at least one episode of CMD) changed the pattern of results from the main analyses.

Adult CMD, the main outcome of interest, was defined as the presence of CMD at wave 10 (average age 35.1 years), ascertained as described above.

\section{Mediators during young adulthood}

In addition to CMD in young adulthood, we considered the following mediators measured at wave 8 (age 24 years): weekly or more frequent cannabis use in the past year (weekly+ cannabis use); no post-school education, defined as not being enrolled in or having obtained a post-school qualification; and having parented a child by age 24 years.

\section{Baseline confounders}

Background confounders were: gender, parental completion of secondary education and parental divorce or separation up to and including wave 6 , and a postcode-based indicator of socioeconomic disadvantage (the Socio-Economic Indexes for Area). ${ }^{17}$ Adolescent confounders were: antisocial behaviour, cannabis use and incompletion of schooling.

Antisocial behaviour over the previous 6 months was evaluated with ten items from the Moffitt and Silva self-report early delinquency scale. ${ }^{18}$ Antisocial behaviour at any wave referred to the 


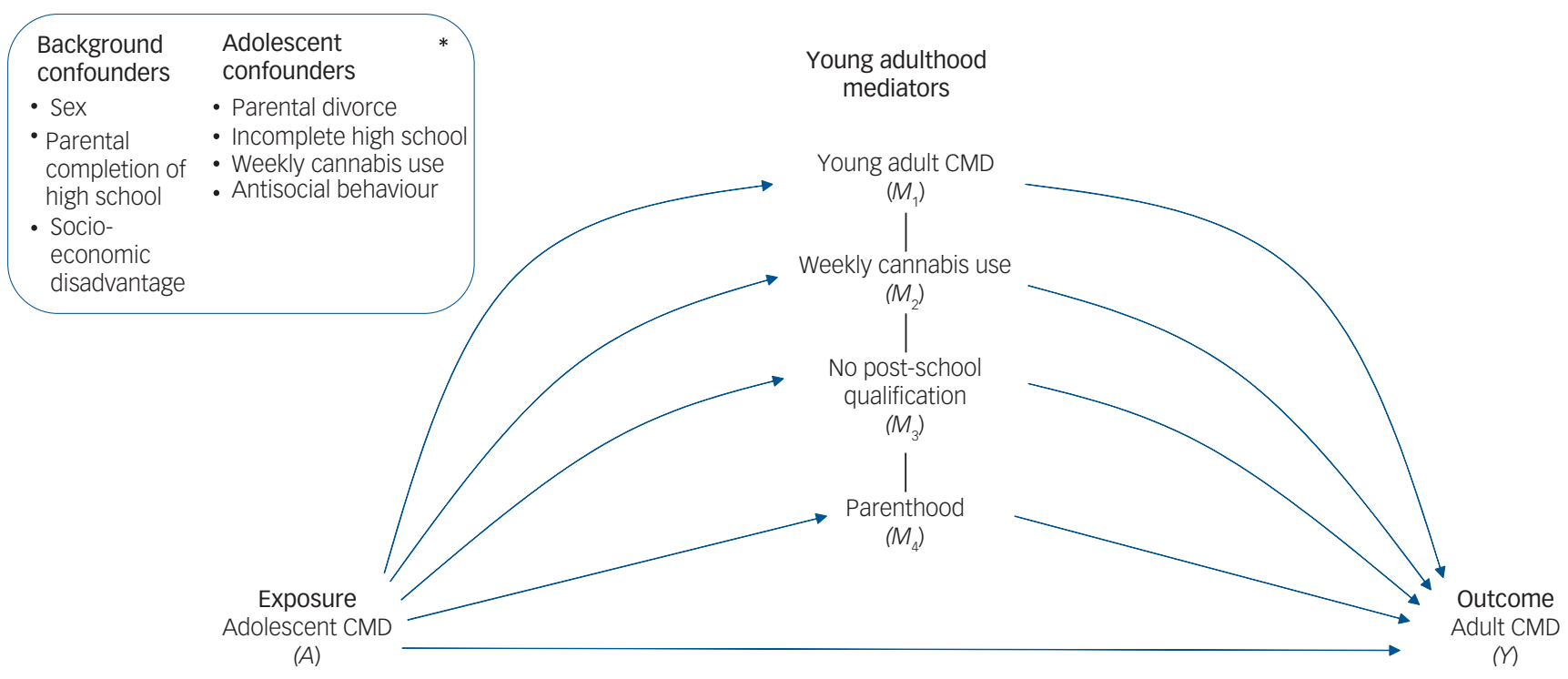

Fig. 2 Directed acyclic graph (DAG) portraying the assumed causal structure, conceptualising the pathways from adolescent common mental disorder (CMD) to CMD in the fourth decade of life, via the four mediators of interest. Undirected arrows indicate where we are agnostic about the directionality of causal influences.

endorsement of one behaviour 'more than once' or two different behaviours at least once.

Weekly+ cannabis use was assessed at each wave using reported frequency of use in the previous 6 months. Incomplete secondary schooling was identified concurrently in waves 2-6 and confirmed in later waves.

Although these adolescent confounders were measured concurrently with exposure (adolescent CMD), we followed recommendations to include them in the confounder set as proxies of otherwise unmeasured prior confounding factors. ${ }^{19}$

\section{Statistical analysis}

Descriptive statistics were obtained for all analysis variables using counts and proportions and respective proportions of missing data in the total sample and by adolescent CMD status. We conducted multiple imputation to handle all missing data in subsequent analyses (details below). All analyses were based on multiply imputed data for the full sample of 1923 participants. All analyses were conducted using Stata version 17 and $\mathrm{R}$ version 3.6.1.

\section{Natural history of adult CMD}

The prevalence of adult CMD was estimated in four-level strata defined in terms of continuity of disorder from adolescence to young adulthood. The proportion of adults with CMD represented by each of these continuity categories was also obtained. We estimated unadjusted and adjusted conditional associations between adolescent disorder, young adult disorder and adult CMD at age 35 years, as well as between adolescent disorder and each mediator, and each mediator and adult CMD. For this purpose, we used maineffects multivariable logistic regression models with adjustment for putative common causes as per Fig. 2 .

\section{Causal analysis}

We estimated the confounder-adjusted difference in prevalence of adult CMD in those with adolescent disorder and those without, using g-computation - also known as regression-standardisation. $^{20,21}$ This causal analytic method enables refined baseline confounding adjustment by accounting for statistical interactions between exposure and covariates. Under a number of assumptions, including that the set of baseline confounders is a sufficient set for confounding adjustment, this adjusted difference can be interpreted as the reduction in prevalence of adult CMD that would be achieved in those with adolescent disorder and in the population if they had not experienced this. As it is unlikely that any intervention would prevent all cases of adolescent disorder, we then used causal mediation analysis to examine the potential benefit of mediator interventions in reducing the prevalence of adult CMD among those with adolescent disorder. This used an extended $g$-computation estimation procedure to evaluate and compare the benefit of intervening on each of multiple interdependent mediators. ${ }^{22-24}$ Specifically, we emulated the effects of the following interventions in individuals with adolescent disorder in terms of the potential reduction in prevalence of adult CMD that would be achieved.

(a) For each mediator, we evaluated the reduction in the prevalence of adult CMD that would be achieved by an intervention that would shift the distribution of the mediator in those with adolescent disorder (the exposed group) to the levels in those without adolescent disorder (the unexposed group). This is achieved by setting the given mediator under exposure to a random draw from its distribution under no exposure, and the rest of the mediators to suitable distributions accounting for the interdependences between them, assuming the ordering $M_{1}, M_{2}, M_{3}, M_{4}$ for this specific analysis (we conducted analyses under alternative interdependence assumptions and conclusions were unchanged as expected ${ }^{22}$ ). The effect of this intervention, which is termed the interventional indirect effect via mediator $k\left(\mathrm{IIE}_{\mathrm{k}}\right)$, is the difference in prevalence before and after this intervention in the exposed group. By estimating and comparing these effects, we can ascertain which single intervention target is most likely to reap benefit in this group. Of note, we consider the unexposed group as the 'healthy benchmark' for mediator levels as in principle, this is a realistic and estimable benchmark.

(b) We evaluated the reduction in prevalence that would be achieved by an intervention that would shift the joint 
distribution of the mediators in the exposed group to the levels in those without adolescent disorder. This is achieved by setting all mediators jointly under exposure to a random draw from their distribution under no exposure. The effect of this intervention, termed the interventional indirect effect via all mediators $\left(\mathrm{IIE}_{\text {all }}\right)$, is the difference in prevalence before and after this intervention, in the exposed group. An estimate of this effect quantifies the maximum benefit that could hope to be achieved in this group by considering all proposed intervention targets jointly. We also estimated the prevalence remaining in the exposed after each intervention, as well as the prevalence remaining in the overall population (exposed and unexposed) and the implied population prevalence reduction.

\section{Multiple imputation}

All variables, except participant gender, were subject to missing data. We used multiple imputation to impute any missing data to minimise the effects of selection bias and non-response. ${ }^{25}$ Multiple imputation by chained equations was used, with $40 \mathrm{impu}-$ tations and a logistic regression imputation model for each incomplete variable including:

(a) all analysis variables;

(b) three auxiliary background variables associated with incomplete participation (school region at entry to the study, parent smoking and drinking status, and participant smoking and drinking status in the week before any adolescent survey);

(c) equivalent wave 7 measures of the three wave 8 mediators, and

(d) all relevant interactions for the mediation models.

When wave 2 observations were missing, the available wave 1 data was carried forward to wave 2 before applying multiple imputation. This strategy was applied to 91 participants with data missing in wave 2 . We considered this reasonable as wave 1 was conducted only 6 months before wave 2 .

\section{Ethics statement}

The authors assert that all procedures contributing to this work comply with the ethical standards of the relevant national and institutional committees on human experimentation and with the Helsinki Declaration of 1975, as revised in 2008. All procedures were approved by the Human Research Committee of the Royal Children's Hospital, Parkville, Victoria 3052, Australia. Informed parental consent was obtained before inclusion in the study. In the adult phase, all participants were informed of the study in writing and gave verbal consent before being interviewed. All verbal consents were recorded in a separate password-secured database, accessible only to members of the assessment team.

\section{Results}

Table 1 shows descriptive statistics, including proportions of missing data for confounders, young adult mediators and CMD at age 35 years, overall and stratified by the occurrence of adolescent CMD.

The proportion of girls was higher in the group with CMD than in those without (77\% v. 48\%). Those with adolescent CMD also had higher rates of incomplete secondary schooling, antisocial behaviour and weekly cannabis use during adolescence than those without.

At wave $10,19.2 \%$ (95\% CI 17.2-21.2 - multiple imputation estimate) of participants had had an episode of CMD in the past 12 months. Table 2 displays multiple imputation estimates of the prevalence of adult CMD stratified by CMD history from adolescence to young adulthood, and by gender.

Over half of those with adolescent CMD did not experience a further episode in the following two decades. In total $42 \%$ of participants identified at 35 years had no prior history of disorder in adolescence or young adulthood. We found that $49 \%$ of those with CMD during both adolescence and young adulthood went on to report CMD in the past 12 months at age 35 years. Thirty-nine per cent of participants who did not have adolescent CMD disorder but developed CMD during the young adult phase of the study reported $\mathrm{CMD}$ at age 35 years. There were no clearly discernible differences in the patterns of continuity in CMD between males and females.

Table 3 displays the results from a series of multivariable logistic regression models examining the associations between:

(a) adolescent CMD and adult CMD at age 35 years (model 1);

(b) adolescent CMD and young adult mediators (model 2); and

(c) young adult mediators and CMD at age 35 years (model $3 \mathrm{~s}$ ).

After adjusting for confounders, we estimated that those with adolescent CMD had over twice the odds of reporting CMD over the past 12 months at age 35 years. Adolescent CMD was more strongly associated with disorder in younger adulthood and, to a lesser extent, with weekly cannabis use at age 24 years and becoming a parent by age 24 .

All mediators of interest were associated with the occurrence of CMD at age 35 years, particularly the occurrence of young adult disorder (odds ratio $(\mathrm{OR})=4.81,95 \%$ CI 3.52-6.57). After adjusting for confounding, including by adolescent CMD, these associations were attenuated but remained elevated, particularly for younger adult disorder (adjusted OR $=3.80,95 \%$ CI 2.72-5.31). The sensitivity analyses produced a pattern of results consistent with the main analyses (see Supplementary Table 1 available at https://doi.org/ 10.1192/bjp.2022.3).

Table 4 displays the results from the causal analysis examining the potential benefit of hypothetical interventions in reducing the prevalence of adult CMD.

With no intervention, the confounder-adjusted prevalence of adult CMD in those with adolescent CMD was estimated to be $29 \%$. A hypothetical intervention that would prevent adolescent CMD would result in a $3.9 \%$ reduction in the population prevalence of CMD at age 35 years. If instead we consider downstream hypothetical interventions in those with adolescent CMD, reducing the joint prevalence of mediators to the level reported by those without adolescent $\mathrm{CMD}$ would result in a $5.8 \%$ reduction in prevalence among those with adolescent $\mathrm{CMD}$, corresponding to only a $1.6 \%$ reduction in population prevalence of CMD at age 35 years.

Considering single mediator interventions, for adolescents with $\mathrm{CMD}$, the highest impact would be achieved by an intervention on young adult $\mathrm{CMD}\left(\mathrm{IIE}_{1}=5.0 \%, 95 \% \mathrm{CI} 2.5\right.$ to $\left.7.6 \%\right)$. The other three intervention targets would have substantially lower potential impact ( $I I E_{2}$ to $I I E_{4}$ between $0.2 \%$ and $0.6 \%$ ), resulting in a negligible reduction in the prevalence of adult CMD, both in those with earlier adolescent CMD and in the overall population. These results were consistent in sensitivity analyses using the less restrictive definition of CMD (see Supplementary Table 2).

\section{Discussion}

\section{Main findings}

Almost one in five participants at the age of 35 years had an episode of CMD in the past 12 months. The prevailing wisdom about adult CMD has been that they are largely an extension of disorders arising 
Table 1 Distribution of background and adolescent characteristics, mediators and outcome in the achieved sample in total, and by exposure status

\begin{tabular}{|c|c|c|c|}
\hline \multirow[b]{3}{*}{ Background, adolescent and young adult measures } & \multirow[b]{2}{*}{ Achieved sample $(n=1923)$} & \multicolumn{2}{|c|}{$\begin{array}{l}\text { Exposure persistent adolescent CMD } \\
\text { (missing } n=687)^{\mathrm{b}}\end{array}$} \\
\hline & & No $(n=920)$ & Yes $(n=316)$ \\
\hline & $n(\%)^{\mathrm{c}}$ & $n(\%)^{\mathrm{c}}$ & $n(\%)^{\mathrm{c}}$ \\
\hline \multicolumn{4}{|l|}{ Background factors } \\
\hline \multicolumn{4}{|l|}{ Gender } \\
\hline Male & $929(48)$ & $475(52)$ & $72(23)$ \\
\hline Female & $994(52)$ & $445(48)$ & $244(77)$ \\
\hline \multicolumn{4}{|l|}{ Parental divorce or separation } \\
\hline No & $1488(77)$ & $776(84)$ & $240(76)$ \\
\hline Yes & $433(23)$ & $144(16)$ & $76(24)$ \\
\hline Missing & 2 & & \\
\hline \multicolumn{4}{|l|}{ Parental secondary school } \\
\hline Completed final year & $1212(66)$ & $641(70)$ & $216(69)$ \\
\hline Left before final year & $612(34)$ & $275(30)$ & $98(31)$ \\
\hline Missing & 99 & 4 & 2 \\
\hline \multicolumn{4}{|l|}{ Index of Relative Socio-economic Disadvantage (1995) } \\
\hline Quintile1 & $386(20)$ & $159(17)$ & $55(18)$ \\
\hline Quintile2 & $381(20)$ & $173(19)$ & $65(21)$ \\
\hline Quintile3 & $388(20)$ & $177(19)$ & $62(20)$ \\
\hline Quintile4 & $383(20)$ & $191(21)$ & $66(21)$ \\
\hline Quintile5 & $374(20)$ & $218(24)$ & $66(21)$ \\
\hline Missing & 11 & 2 & 2 \\
\hline \multicolumn{4}{|l|}{ Adolescent covariates } \\
\hline \multicolumn{4}{|l|}{ Antisocial behaviour ${ }^{d}$} \\
\hline No & $1566(82)$ & $801(87)$ & $248(78)$ \\
\hline Yes & $341(18)$ & $119(13)$ & $68(22)$ \\
\hline Missing & 16 & & \\
\hline \multicolumn{4}{|l|}{ Weekly+ cannabis use $e^{d}$} \\
\hline No & $1675(88)$ & 841 (92) & $269(85)$ \\
\hline Yes & $220(12)$ & $78(8)$ & $47(15)$ \\
\hline Missing & 28 & 1 & 0 \\
\hline \multicolumn{4}{|l|}{ Secondary school } \\
\hline Completed final year & $1483(83)$ & $852(93)$ & $279(88)$ \\
\hline Left before final year & $311(17)$ & $67(7)$ & $37(12)$ \\
\hline Missing & 129 & 1 & 0 \\
\hline \multicolumn{4}{|l|}{ Young adult mediators } \\
\hline \multicolumn{4}{|l|}{ Persistent $\mathrm{CMD}^{\mathrm{b}}$} \\
\hline No & $1532(88)$ & $825(93)$ & $219(72)$ \\
\hline Yes & $214(12)$ & $61(7)$ & $84(28)$ \\
\hline Missing & 177 & 34 & 13 \\
\hline \multicolumn{4}{|l|}{ Weekly+ cannabis use ${ }^{\mathrm{e}}$} \\
\hline No & $1320(88)$ & $728(92)$ & $237(87)$ \\
\hline Yes & $186(12)$ & $66(8)$ & $34(13)$ \\
\hline Missing & 417 & 126 & 45 \\
\hline \multicolumn{4}{|l|}{ Post-school educatione } \\
\hline No & $983(65)$ & $555(70)$ & $170(63)$ \\
\hline Yes & $525(35)$ & $240(30)$ & $101(37)$ \\
\hline Missing & 415 & 125 & 45 \\
\hline \multicolumn{4}{|l|}{ Parenthoode } \\
\hline No & $1377(91)$ & $757(95)$ & $244(90)$ \\
\hline Yes & $131(9)$ & $38(5)$ & $26(10)$ \\
\hline Missing & 415 & 125 & 46 \\
\hline \multicolumn{4}{|l|}{ Adult outcome } \\
\hline $\mathrm{CMD}^{\mathrm{f}}$ & & & \\
\hline No & $1181(82)$ & $645(87)$ & $198(74)$ \\
\hline Yes & $261(18)$ & $97(13)$ & $70(26)$ \\
\hline Missing & 481 & 178 & 48 \\
\hline $\begin{array}{l}\text { a. Common mental disorders (CMD): CMD identified in two or mo } \\
\text { b. Missing by wave: } 215(11 \%) \text { in wave } 2,242(13 \%) \text { in wave } 3,309 \text { ( } \\
\text { when observations were missing in wave } 2 \text {. } \\
\text { c. Per cent of available data. } \\
\text { d. Any occurrence from wave } 2 \text { to } 6 \text { (15-17 years). } \\
\text { e. Measured at wave } 8 \text { ( } 24 \text { years). } \\
\text { f. Measures at wave } 10 \text { ( } 35 \text { years). }\end{array}$ & $\begin{array}{l}\text { adolescent phase (waves } 2-6,15- \\
1(16 \%) \text { in wave } 5 \text { and } 406(21 \%) \text { in wa }\end{array}$ & $\begin{array}{l}\text { In the young adult } \\
\text { forward wave } 1 \mathrm{c}\end{array}$ & $\begin{array}{l}9,20-29 \text { years). } \\
\text { pants to wave } 2\end{array}$ \\
\hline
\end{tabular}

during adolescence. ${ }^{6,26}$ Yet, over $40 \%$ of these participants had no prior CMD either during adolescence or young adulthood and one in eight participants with no history of CMD in adolescence or young adulthood went on to experience an episode of CMD in their fourth decade.
The findings also suggest that many individuals recover from earlier CMD in adolescence. Over half of those with adolescent CMD had no further episodes detected in the following two decades. The causal analyses revealed that, in principle, the prevention of adolescent CMD could reduce the population prevalence of 
Table 2 Continuity in common mental disorder (CMD) from adolescence to young adulthood, with frequency of adult CMD, in total and by gender ${ }^{a}$

\begin{tabular}{|c|c|c|c|c|c|}
\hline \multicolumn{2}{|c|}{ Continuity of CMD in the past } & \multicolumn{2}{|c|}{$\begin{array}{l}\text { Adult CMD } \\
\text { (35 years, } \\
\text { wave 10) }\end{array}$} & \multicolumn{2}{|c|}{ Proportion with adult $\mathrm{CMD}$} \\
\hline $\begin{array}{l}\text { Adolescent CMD } \\
\text { (waves 2-6) }\end{array}$ & $\begin{array}{l}\text { Young adult CMD } \\
\text { (waves 7-9) }\end{array}$ & $\begin{array}{l}\text { No, } \\
n^{\text {d }}\end{array}$ & $\begin{array}{l}\text { Yes, } \\
n^{\mathrm{d}}\end{array}$ & $\begin{array}{l}\text { Among total in continuity group (row \%), } \\
\qquad \%(95 \% \mathrm{Cl})\end{array}$ & $\begin{array}{l}\text { Among total with adult CMD (column \%), } \\
\qquad \%(95 \% \mathrm{Cl})\end{array}$ \\
\hline \multicolumn{6}{|c|}{ Adolescent CMD, total } \\
\hline No & $\begin{array}{l}\text { No } \\
\text { Yes }\end{array}$ & $\begin{array}{r}1107 \\
78\end{array}$ & $\begin{array}{r}154 \\
49\end{array}$ & $\begin{array}{l}12(10 \text { to } 15) \\
39(29 \text { to } 49)\end{array}$ & $\begin{array}{l}42(35 \text { to } 48) \\
13(9 \text { to } 17)\end{array}$ \\
\hline & No & 275 & 77 & 22 (17 to 27 ) & 21 (16 to 26 ) \\
\hline Yes & Yes & 94 & 89 & 49 (40 to 57$)$ & 24 (19 to 29 ) \\
\hline \multicolumn{6}{|c|}{ Adolescent CMD, male } \\
\hline No & $\begin{array}{l}\text { No } \\
\text { Yes }\end{array}$ & $\begin{array}{r}538 \\
38\end{array}$ & $\begin{array}{l}75 \\
23\end{array}$ & $\begin{array}{l}12(8 \text { to } 16) \\
38(12 \text { to } 63)\end{array}$ & $\begin{array}{l}44 \text { (1 to } 86) \\
13 \text { (3 to } 23 \text { ) }\end{array}$ \\
\hline Yes & No & 130 & 38 & 22 (11 to 34 ) & 20 (10 to 31) \\
\hline \multicolumn{6}{|c|}{ Adolescent CMD, female } \\
\hline No & $\begin{array}{l}\text { No } \\
\text { Yes }\end{array}$ & $\begin{array}{r}479 \\
41\end{array}$ & $\begin{array}{l}63 \\
32\end{array}$ & $\begin{array}{l}12(8 \text { to } 15) \\
44(31 \text { to } 57)\end{array}$ & $\begin{array}{l}30(23 \text { to } 37) \\
15(10 \text { to } 21)\end{array}$ \\
\hline Yes & $\begin{array}{l}\text { No } \\
\text { Yes }\end{array}$ & $\begin{array}{r}187 \\
76\end{array}$ & $\begin{array}{l}48 \\
68\end{array}$ & $\begin{array}{l}20 \text { (14 to } 26) \\
47 \text { (37 to } 58)\end{array}$ & $\begin{array}{l}23(16 \text { to } 29) \\
32(25 \text { to } 40)\end{array}$ \\
\hline $\begin{array}{l}\text { a. Results based on mu } \\
\text { b. CMD identified in twc } \\
\text { c. CMD identified in twc } \\
\text { d. Numbers estimated } \mathrm{u} \\
\text { of the proportion with a }\end{array}$ & $\begin{array}{l}\text { mputed data for the } \\
\text { ore waves in the add } \\
\text { ore waves in in the } y \\
\text { ultiple imputation es } \\
\text { MDD to estimate num }\end{array}$ & & & $\begin{array}{l}\text { rticipant numbers ( } n \text { ) are estimated using multip } \\
\text { years). } \\
-28 \text { years). } \\
\text { iplied by sample size; estimate row total, whichv } \\
\text { nplement being the number without adult CMD. }\end{array}$ & $\begin{array}{l}\text { itation proportion estimates so totals may vary. } \\
\text { n multiplied by the multiple imputation estimate }\end{array}$ \\
\hline
\end{tabular}

CMD occurring at age 35 by $3.9 \%$, but this would still leave a population prevalence of $15 \%$, as a result of the large number of new cases arising in the unexposed group in their third and fourth decades. For those with adolescent CMD, the introduction of interventions in young adulthood alone is unlikely to substantially reduce their later risk for CMD, or bring about a substantial reduction in the later community prevalence of these disorders.

Our definition of adolescent and young adult CMD (the persistence of 'caseness' over two or more waves of follow-up) represents a level and persistence of disorder where an intervention is likely to be indicated and therefore captured a clinically meaningful exposure. Yet, this definition will not have captured the occurrence of single episodes of CMD. We therefore ran sensitivity analyses using a less restrictive definition of CMD to see what impact this had on the findings. Although the size of some point estimates was marginally reduced in the sensitivity analyses, the overall pattern of associations was identical.

\section{Comparison with findings from other studies}

Few studies have charted the course of CMD from adolescence into later adult life and to our knowledge, no previous population-based study has used causal analytic methods to quantify the impact of early intervention on the prevalence of later CMD. A recent systematic review ${ }^{10}$ identified two population-based studies that assessed CMD in adolescence, and again in the fourth decade of life, using diagnostic assessments. Using data from 995 participants in the Christchurch Health and Development Study, McLeod et $\mathrm{al}^{7}$ found that adolescents with clinical depression were at increased risk of both anxiety and depression at age 30-35, although they also noted that the associations were modest and that less than $10 \%$ of major depression at age 35 was because of adolescent depression (population attributable risk \%: 6.9\%). Similarly, in a sample of 382 participants in the Uppsala Longitudinal Adolescent Depression Study, Jonsson et $\mathrm{al}^{6}$ found that adolescent depression predicted anxiety disorder at age 30-35. These associations were most pronounced for adolescents with long-term adolescent depression; adult anxiety disorders were present among $63 \%$ of adolescents with long-term depression, compared with $32 \%$ of adolescents with episodic depression.
The multivariable logistic regression models showed that the occurrence of CMD during the young adult years independently predicted $\mathrm{CMD}$ at age 35 , a finding that is consistent with other prospective research. ${ }^{27}$ Weekly cannabis use and early parenthood were also associated with CMD at age 35, although the size of these associations was less than that observed with young adult CMD. Our causal modelling showed that among those with prior adolescent $\mathrm{CMD}$, the reduction in prevalence that could be achieved by correcting the imbalance in the distribution of these mediators jointly would only be $5.8 \%$, amounting to a $1.6 \%$ reduction in the overall prevalence of CMD at age 35. Our findings also show that, for those with prior adolescent disorder, the single best target for intervention in their 20s would be a reduction in the prevalence of CMD - an intervention that could in itself reduce the prevalence in those with earlier adolescent disorder by $5 \%$. In contrast, other policies designed to widen access to education, reduce cannabis consumption and reduce the incidence of parenthood in the early 20 s, appeared to have negligible effects on the prevalence of CMD in the fourth decade. Such policies may reap wider social and health benefits, but our data suggest that intervening on these mediational targets would not, in their own right, significantly change the course of CMD. We selected these potential mediators for evaluation $a$ priori because they are all potential modifiable targets. Yet it is possible that greater benefits might be achieved by targeting other processes, such as instability of employment, relationships and economic problems. ${ }^{28}$

\section{Strengths and limitations}

The findings need to be considered in the light of several strengths and limitations. A key limitation of our study, shared by most prospective cohorts of this kind, is that we were not able to evaluate actual interventions that have been implemented in the real world; instead, we evaluated the benefit of hypothetical interventions shifting intervention targets to a given benchmark. ${ }^{29}$ Our analyses are reliant on assumptions of no residual confounding (of exposure-outcome, mediator-outcome, and exposure-mediator associations), a missing at random assumption, given the variables included in the imputation model, and an assumption of ignorable measurement error. Although we adjusted for a range of baseline 
Table 3 Associations between adolescent common mental disorder (CMD) and adult CMD (model 1); adolescent CMD and each young adulthood mediator (model 2); and each young adult mediator and adult CMD (model 3); estimates obtained using multiply imputed data for the full cohort of 1923 participants

\begin{tabular}{|c|c|c|c|}
\hline Model and exposure & $\begin{array}{c}\text { Outcome } \\
\text { prevalence\% }{ }^{\mathrm{a}}\end{array}$ & $\begin{array}{l}\text { Odds ratio (OR) } \\
(95 \% \mathrm{Cl})^{\mathrm{b}}\end{array}$ & $\begin{array}{l}\text { Adjusted odds ratio (AOR) } \\
\qquad(95 \% \mathrm{Cl})^{\mathrm{c}}\end{array}$ \\
\hline \multicolumn{4}{|c|}{ Model 1: exposure, adolescent CMD; outcome, adult CMD } \\
\hline No (ref) & 15 & 1 & 1 \\
\hline Yes & 31 & $2.61(1.92-3.54)$ & $2.36(1.72-3.25)$ \\
\hline \multicolumn{4}{|c|}{ Model 2: exposure, adolescent CMD; outcome, young adulthood mediators } \\
\hline \multicolumn{4}{|c|}{ Outcome, young adult CMD (20-29 years $)^{d}$} \\
\hline No (ref) & 9 & 1 & 1 \\
\hline Yes & 34 & $5.17(3.79-7.06)$ & $4.01(2.86-5.63)$ \\
\hline \multicolumn{4}{|c|}{ Outcome, weekly+ cannabis use (24 years) } \\
\hline No (ref) & 12 & 1 & 1 \\
\hline Yes & 19 & $1.77(1.29-2.41)$ & $1.87(1.26-2.76)$ \\
\hline \multicolumn{4}{|c|}{ Outcome, no post-school qualification/enrolment (24 years) } \\
\hline No (ref) & 35 & 1 & 1 \\
\hline Yes & 40 & $1.21(0.96-1.53)$ & $1.13(0.88-1.47)$ \\
\hline \multicolumn{4}{|c|}{ Outcome, parenthood (24 years) } \\
\hline No (ref) & 8 & 1 & 1 \\
\hline Yes & 16 & $2.06(1.42-2.99)$ & $1.60(1.03-2.49)$ \\
\hline \multicolumn{4}{|c|}{ Model 3: exposure, young adulthood mediators; outcome, adult CMD (35 years) } \\
\hline \multicolumn{4}{|c|}{ Exposure, young adult CMD (20-29 years) } \\
\hline No (ref) & 14 & 1 & 1 \\
\hline Yes & 45 & $4.81(3.52-6.57)$ & $3.80(2.72-5.31)$ \\
\hline \multicolumn{4}{|c|}{ Exposure, weekly+ cannabis use (24 years) } \\
\hline No (ref) & 18 & 1 & 1 \\
\hline Yes & 29 & $1.87(1.31-2.67)$ & $1.66(1.10-2.51)$ \\
\hline \multicolumn{4}{|c|}{ Exposure, no post-school qualification/enrolment (24 years) } \\
\hline No (ref) & 17 & 1 & 1 \\
\hline Yes & 23 & 1.44 (1.09-1.91) & $1.27(0.94-1.71)$ \\
\hline \multicolumn{4}{|c|}{ Exposure, parenthood (24 years) } \\
\hline No (ref) & 18 & 1 & 1 \\
\hline Yes & 32 & $2.15(1.46-3.16)$ & $1.64(1.08-2.49)$ \\
\hline \multicolumn{4}{|c|}{$\begin{array}{l}\text { AOR, adjusted odds ratio; Ref, reference. } \\
\text { a. Multitle imputation estimates, thus crude odds ratio does not coincide exactly with multiple imputation estimates of crude ORs from univariable logistic models. } \\
\text { b. Multiple imputation estimates of odds ratios from univariable logistic regression models. } \\
\text { c. Multiple imputation estimates of odds ratios from multivariable logistic regression models. All models adjusted for possible background confounders (gender, parental separated/divorce, } \\
\text { socieconomic disadvantage and education) and adolescent confounders (any antisocial behaviour, any weekly+ cannabis use, incomplete high school). In addition, all model } 3 \text { data are also } \\
\text { adjusted for adolescent CMDD. } \\
\text { d. Commmon mental disorders (CMD): CMD identified in two or more waves in (a) the adolescent phase (waves 2-6, 15-17 years) and (b) in the young adult phase (waves 7-9, 20-28 years). } \\
\text { Adult CMD measured in wave } 10 \text { (35 years). }\end{array}$} \\
\hline
\end{tabular}

confounders and used multiple imputation incorporating auxiliary variables to relax assumptions about missing data, these assumptions might still not hold true and it is possible that our estimates are biased. A further possible limitation was the use of different measures for depression and anxiety in young adulthood; the GHQ and CIDI-Short Form are often viewed as screens rather than diagnostic measures, and their use may have led to incorrect inferences about the continuity of CMD.

Table 4 Results from causal mediation analysis: estimated effects on prevalence of adult common mental disorder (CMD) of hypothetical interventions in individuals with persistent adolescent CMD; estimates obtained using multiply imputed data for the full cohort of 1923 participants

\begin{tabular}{|c|c|c|c|c|c|}
\hline \multirow[b]{2}{*}{$\begin{array}{l}\text { Effects on prevalence of adult CMD of } \\
\text { hypothetical interventions in individuals with } \\
\text { persistent adolescent CMD }\end{array}$} & \multicolumn{5}{|c|}{ Adult CMD } \\
\hline & $\begin{array}{l}\text { Prevalence reduction in } \\
\text { exposed (\%) } 95 \% \mathrm{Cl}\end{array}$ & $P$ & $\begin{array}{l}\text { Prevalence } \\
\text { remaining in } \\
\text { exposed }(\%)\end{array}$ & $\begin{array}{l}\text { Prevalence } \\
\text { remaining in } \\
\text { population (\%) }\end{array}$ & $\begin{array}{l}\text { Prevalence reduction } \\
\text { in population (\%) }\end{array}$ \\
\hline No intervention & - & - & 29.0 & 18.9 & - \\
\hline $\begin{array}{l}\text { Intervention eliminating persistent adolescent } \\
\text { CMD (TCE) } \\
\text { Intervention lowering level of a given mediator } \\
\text { to that in the unexposed }{ }^{\mathrm{C}}\end{array}$ & $14.0(8.4$ to 19.5$)$ & $<0.001$ & 15.0 & 15.0 & 3.9 \\
\hline Young adult persistent CMD (IIE1) & $5.0(2.5$ to 7.6$)$ & $<0.001$ & 24.0 & 17.5 & 1.4 \\
\hline Weekly+ cannabis use (IIE2) & $0.4(-0.6$ to 1.5$)$ & 0.429 & 28.6 & 18.8 & 0.1 \\
\hline No post-school qualifications/enrolment (IIE3) & $0.2(-0.4$ to 0.8$)$ & 0.572 & 28.8 & 18.9 & 0.0 \\
\hline Parenthood (IIE4) & $0.6(-0.4$ to 1.5$)$ & 0.236 & 28.4 & 18.8 & 0.1 \\
\hline $\begin{array}{l}\text { Intervention jointly lowering all mediators to } \\
\text { levels in unexposed (IIE-All) })^{d}\end{array}$ & 5.8 (2.9 to 8.7$)$ & $<0.001$ & 23.2 & 17.3 & 1.6 \\
\hline \multicolumn{6}{|c|}{$\begin{array}{l}\text { a. All estimates are adjusted for background confounders (gender, parental separated/divorce, socioeconomic disadvantage and education) and adolescent confounders (any antisocial } \\
\text { behaviour, any weekly+ cannabis use, incomplete high school). They were obtained via a g-computation procedure with multiply imputed data. } \\
\text { b. The total causal effect (TCE) is the prevalence difference comparing prevalence under exposure versus no exposure. } \\
\text { c. Set given mediator under exposure to a random draw from its distribution under no exposure. The corresponding interventional indirect effect (IIE) is the prevalence difference comparing } \\
\text { prevalence before and after this intervention under exposure. } \\
\text { d. Set all mediators jointly under exposure to a random draw from their distribution under no exposure. The corresponding intervention indirect effect (IIE-All) is the prevalence difference } \\
\text { comparing prevalence before and after this intervention under exposure. }\end{array}$} \\
\hline
\end{tabular}


Although our prospective cohort design with an extended follow-up allowed us to investigate the effect of intervening on four selected policy-relevant mediators, including young adult $\mathrm{CMD}$, we did not investigate the impact of intervening specifically on key psychological mediators, such as problem-solving or interpersonal skills. Finally, our findings are based on an Australian cohort from one region of the country, and may not be generalisable to other settings, particularly in low- and middle-income countries.

In terms of strengths, to our knowledge, this is the largest prospective population-based study to date investigating the continuity of CMD into the fourth decade of life. Our multiwave approach allowed us to capture important mediating variables on the causal pathway. Furthermore, uniquely, we used causal analytic methods, a key feature of which is to estimate effects that are defined, not in terms of a parameter in a regression model (for example a regression coefficient) but rather in terms of a hypothetical 'target trial'. ${ }^{29}$ This enables enhanced interpretability of findings and tighter adjustment for confounding and other biases to better inform future trials and implementation

\section{Implications}

The need for early intervention in youth has received a great deal of emphasis in recent mental health policy, premised on assumptions about the adolescent onset of CMD and their persistence into adulthood. ${ }^{30}$ Yet, prospective investigation of the natural history of these disorders suggests that time-limited clinical interventions in those with adolescent-onset disorders will have little impact on the prevalence of later episodes of CMD. ${ }^{31}$ In part, this is because many adolescent disorders resolve by young adulthood, and because new cases of people with CMD emerge later in life. Indeed, others have observed that the experience of 'enduring mental health' is a rare phenomenon, with most people developing a diagnosable mental disorder at some point in their life, most commonly depression or anxiety. ${ }^{32}$ Collectively, these observations suggest the need for a life-course approach in tackling the burden of disease associated with CMD. Policymakers should recognise that depression and anxiety arise in the context of a range of adversities occurring not just in childhood or adolescence, but extending well into adulthood and that time-limited intervention across a narrow age band is unlikely to produce substantial benefits for individuals and society. These findings may partially explain why, although there has been a substantial increase in the number of young people receiving mental health treatment over the past two decades, ${ }^{33}$ this has so far failed to reduce the population prevalence of CMD.

Paul Moran (D), MD, Centre for Academic Mental Health, Department of Population Health Sciences, Bristol Medical School, University of Bristol, UK; Margarita MorenoBetancur, PhD, Clinical Epidemiology \& Biostatistics Unit, Murdoch Children's Research Institute, and Department of Paediatrics, University of Melbourne, Australia; Carolyn Coffey, PhD, Centre for Adolescent Health, Royal Children's Hospital Murdoch Children's Research Institute, Australia; Elizabeth A. Spry, PhD, , Centre for Adolescent Health, Royal Children's Hospital Murdoch Children's Research Institute, Australia; and Centre for Social and Early Emotional Development, Deakin University, Australia; George C. Patton, MD, Centre for Adolescent Health, Royal Children's Hospital Murdoch Children's Research Institute, Australia

Correspondence: Paul Moran. Email: paul.moran@bristol.ac.uk

First received 24 Sep 2021, final revision 5 Jan 2022, accepted 05 Jan 2022

\section{Supplementary material}

To view supplementary material for this article, please visit https://doi.org/10.1192/bjp.2022.3.

\section{Data availability}

The data that support the findings of this study are available from G.C.P., upon reasonable request.

\section{Acknowledgements}

P.M. is part-funded by the NIHR Biomedical Research Centre at University Hospitals Bristol and Weston NHS Foundation Trust and the University of Bristol and also receives salary support from Avon \& Wiltshire Mental Health Partnership NHS Trust. The views expressed are those of the author(s) and not necessarily those of the NIHR or the Department of Health and Social Care.

\section{Author contributions}

G.C.P. M.M.-B. and P.M. conceived the idea for the study. P.M. led the writing and editing of the paper. M.M.-B. conducted the statistical analyses and C.C. assisted with the analysis. All authors assisted with interpretation of the findings and editing of the final version of the manuscript. G.C.P. is the senior investigator on VAHCS.

\section{Funding}

Data collection for this study was supported by NHMRC Australia and the Victorian Government's Operational Infrastructure Support Program. M.M.-B. is the recipient of an Australian Research Council Discovery Early Career Award (project number DE190101326) funded by the Australian Government. P.M. is part-funded by the NIHR Biomedical Research Centre at University Hospitals Bristol and Weston NHS Foundation Trust and the University of Bristol and also receives salary support from Avon \& Wiltshire Mental Health Partnership NHS Trust. The views expressed are those of the author(s) and not necessarily those of the NIHR or the Department of Health and Social Care.

\section{Declaration of interest}

None

\section{References}

1 Turecki G, Brent DA. Suicide and suicidal behaviour. Lancet 2016; $\mathbf{3 8 7}$ 1227-39.

2 World Health Organization. Depression and Other Common Mental Disorders: Global Health Estimates. World Health Organization, 2017.

3 Kessler RC, Angermeyer M, Anthony JC RDEG, Demyttenaere K, Gasquet I, et al. Lifetime prevalence and age-of-onset distributions of mental disorders in the World health organization's world mental health survey initiative. World Psychiatry 2007; 6: 168-76.

4 McGorry PD, Purcell R, Goldstone S, Amminger GP. Age of onset and timing of treatment for mental and substance use disorders: implications for preventive intervention strategies and models of care. Curr Opin Psychiatry 2011; 24: 301-6.

5 McGorry PD, Purcell R, Hickie IB, Jorm AF. Investing in youth mental health is a best buy. Med J Aust 2007; 187(S7): S5-S7.

6 Jonsson $\mathrm{U}$, Bohman $\mathrm{H}$, von Knorring L, Olsson G, Paaren A, von Knorring AL. Mental health outcome of long-term and episodic adolescent depression: 15-year follow-up of a community sample. J Affect Disord 2011; 130: 395-404.

7 McLeod GF, Horwood LJ, Fergusson DM. Adolescent depression, adult mental health and psychosocial outcomes at 30 and 35 years. Psychol Med 2016; 46: 1401-12.

8 Moffitt TE, Harrington $\mathrm{H}$, Caspi A, Kim-Cohen J, Goldberg D, Gregory AM, et al. Depression and generalized anxiety disorder: cumulative and sequential comorbidity in a birth cohort followed prospectively to age 32 years. Arch Gen Psychiatry 2007; 64: 651-60.

9 Copeland W, Shanahan L, Costello EJ, Angold A. Cumulative prevalence of psychiatric disorders by young adulthood: a prospective cohort analysis from the great smoky mountains study. J Am Acad Child Adolesc Psychiatry 2011; 50: 252-61.

10 Johnson D, Dupuis G, Piche J, Clayborne Z, Colman I. Adult mental health outcomes of adolescent depression: a systematic review. Depress Anxiety 2018; 35: 700-16.

11 Gobbi G, Atkin T, Zytynski T, Wang S, Askari S, Boruff J, et al. Association of cannabis use in adolescence and risk of depression, anxiety, and suicidality in young adulthood: a systematic review and meta-analysis. JAMA Psychiatry 2019; 76: 426-34.

12 Fergusson DM, Woodward LJ. Mental health, educational, and social role outcomes of adolescents with depression. Arch Gen Psychiatry 2002; 59 225-31.

13 Lewis G, Pelosi AJ, Araya R, Dunn G. Measuring psychiatric disorder in the community: a standardized assessment for use by lay interviewers. PsycholMed 1992; 22: 465-86. 
14 Goldberg DP, Gater R, Sartorius N, Ustun TB, Piccinelli M, Gureje O, et a The validity of two versions of the GHQ in the WHO study of mental illness in general health care. Psychol Med 1997; 27: 191-7.

15 World Health Organization. Composite International Diagnostic Interview CIDI-auto 2.1 Administrator's Guide and Reference. WHO, 1997

16 Kessler RC, Andrews G, Mroczek D, Ustun B, Wittchen HU. The World Health Organization Composite International Diagnostic Interview Short Form (CIDI SF). Int J Methods Psychiatr Res 1998; 7: 171-85.

17 Australian Bureau of Statistics. Census of Population and Housing: SocioEconomic Indexes for Areas (SEIFA), Australia, 2011. Australian Bureau of Statistics, 2011 (https://www.abs.gov.au/ausstats/abs@.nsf/DetailsPage/ 2033.0.55.0012011 [cited 26 Jan 2022]).

18 Moffitt TE, Silva PA. Self-reported delinquency: results from an instrument for New Zealand. Aust N Z J Criminol 1988; 21: 227-40.

19 VanderWeele TJ. Principles of confounder selection. Eur J Epidemiol 2019; 34 211-9.

20 Hernán M, Robins J. Causal Inference: What If. Chapman \& Hall/CRC, 2020.

21 Vansteelandt S, Keiding N. Invited commentary: G-computation-lost in translation? Am J Epidemiol 2011; 173: 739-42.

22 Moreno-Betancur M, Moran P, Becker D, Patton GC, Carlin JB. Mediation effects that emulate a target randomised trial: simulation-based evaluation of ill-defined interventions on multiple mediators. Stat Methods Med Res 2021; 30(6): 1365-412.

23 VanderWeele TJ, Robinson WR. On the causal interpretation of race in regressions adjusting for confounding and mediating variables. Epidemiology 2014; 25: 473-84.

24 Vansteelandt S, Daniel RM. Interventional effects for mediation analysis with multiple mediators. Epidemiology 2017; 28: 258-65.

25 Rubin DB. Multiple Imputation for Non-Response in Surveys. John Wiley \& Sons Inc, 1987.
26 Kim-Cohen J, Caspi A, Moffitt TE, Harrington H, Milne BJ, Poulton R. Prior juvenile diagnoses in adults with mental disorder: developmental follow-back of a prospective-longitudinal cohort. Arch Gen Psychiatry 2003 60: 709-17.

27 Clark C, Rodgers B, Caldwell T, Power C, Stansfeld S. Childhood and adulthood psychological ill health as predictors of midlife affective and anxiety disorders: the 1958 British birth cohort. Arch Gen Psychiatry 2007; 64: 668-78.

28 Wickrama KA, Conger RD, Lorenz FO, Martin M. Continuity and discontinuity of depressed mood from late adolescence to young adulthood: the mediating and stabilizing roles of young adults' socioeconomic attainment. J Adolesc 2012; 35: 648-58.

29 Moreno-Betancur $M$. The target trial: a powerful device beyond well-defined interventions. Epidemiology 2021; 32: 291-4.

30 Malla A, Shah J, lyer S, Boksa P, Joober R, Andersson N, et al. Youth mental health should be a top priority for health care in Canada. Can J Psychiatry 2018; 63: 216-22.

31 Seidler ZE, Rice SM, Dhillon HM, Cotton SM, Telford NR, McEachran J, et al. Patterns of youth mental health service use and discontinuation: population data from Australia's headspace model of care. Psychiatr Serv 2020; 71: 1104-13.

32 Schaefer JD, Caspi A, Belsky DW, Harrington H, Houts R, Horwood LJ, et al. Enduring mental health: prevalence and prediction. J Abnorm Psychol 2017 126: $212-24$.

33 Olfson M, Druss BG, Marcus SC. Trends in mental health care among children and adolescents. N Engl J Med 2015; 372: 2029-38. 